\title{
Value of a hybrid PET/MRI in the assessment of cardiac viability
}

\author{
David Carballo ${ }^{1 *}$, René Nkoulou', Gabriella Vincenti ${ }^{1}$, Alessandra Quercioli', Susanne Heinzer ${ }^{1}$, Dominique Didier ${ }^{1}$, \\ Matthias Stuber ${ }^{2}$, Thomas Schindler ${ }^{1}$, Osman Ratib', Jean Vallee ${ }^{1}$ \\ From 15th Annual SCMR Scientific Sessions \\ Orlando, FL, USA. 2-5 February 2012
}

\section{Summary}

Hybrid PET/MRI imaging techniques are become more readily available, and its role in viability assessment appears promising.

\section{Background}

We evaluated the potential for hybrid PET/MRI devices to provide integrated metabolic, functional and anatomic characterization of patients with fixed hypoperfusion on cardiac SPECT.

\section{Methods}

A pilot study of eleven patients (6 fixed hypoperfusion on cardiac SPECT and 5 healthy volunteers) performed an imaging study using a hybrid PET/MRI (Philips). Viability assessed by 18F-FDG was performed in diseased patients along with MRI anatomic, functional and viability assessment as determined by transmural extent of late gadolinium enhancement (LGE). A reassessment by conventional PET/CT was carried out within $30 \mathrm{~min}$ utes. Non-contrast right coronary artery (RCA) targeted and whole heart 3D coronary angio-MRI using ECGgating and respiratory navigator was performed in healthy volunteers with reconstruction performed using MPR and volume rendering. The extent of metabolic defect (MD) using PET/MRI and PET/CT were compared in patients and coronary territories (LAD, CX, RCA). Assessibility of coronary lumen was judged as good, sub-optimal or non-assessable using a 16-segments coronary model.

\section{Results}

Direct comparison of myocardial viability as assessed by MRI LGE and Pet metabolism revealed consistent results in 4 of the 6 diseased patients, and discordant results in the other two. Of note, one discordant result was potentially due to suboptimal attenuation correction in the case of a hypertrophied left ventricle. Metabolic assessment was successful in all patients with MD being $19.2 \%$ vs $18.3 \%$ using PET/MRI and PET/CT, respectively $(\mathrm{P}=\mathrm{ns})$. The MD was $10.2 \%, 6 \%$, and $3 \%$ vs $9.3 \%$, $6 \%$ and $3 \%$ for LAD, CX and RCA territories, respectively $(\mathrm{P}=\mathrm{ns})$. Coronary angio-MRI was successful in all volunteers with 66 coronary segments visualized overall. The RCA was fully visualized in $4 / 5$ volunteers and the left coronary arteries in 4/5 volunteers. Assessibility in

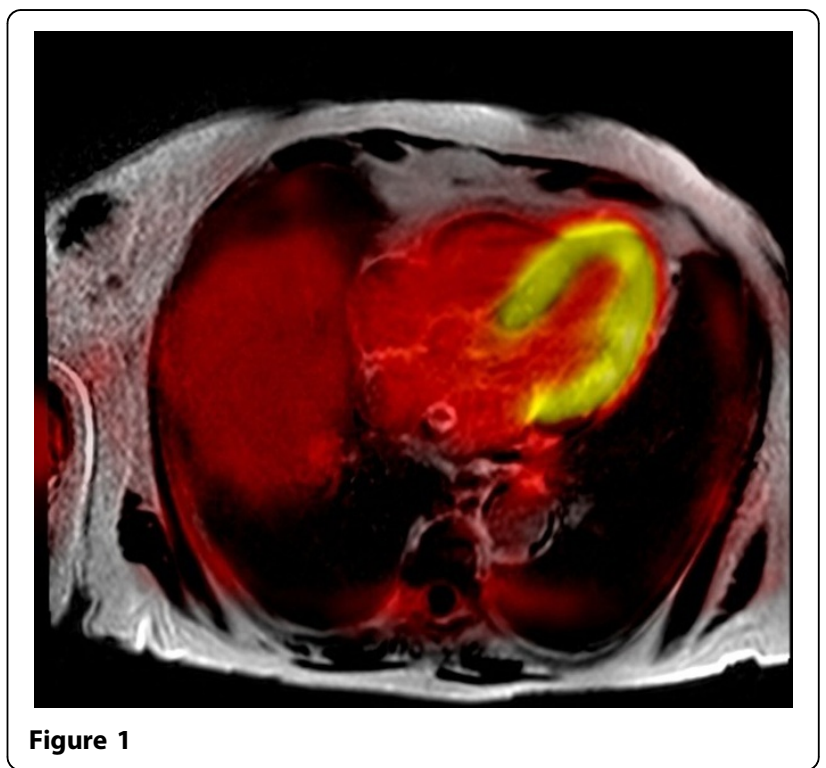

(C) 2012 Carballo et al; licensee BioMed Central Ltd. This is an open access article distributed under the terms of the Creative Commons 


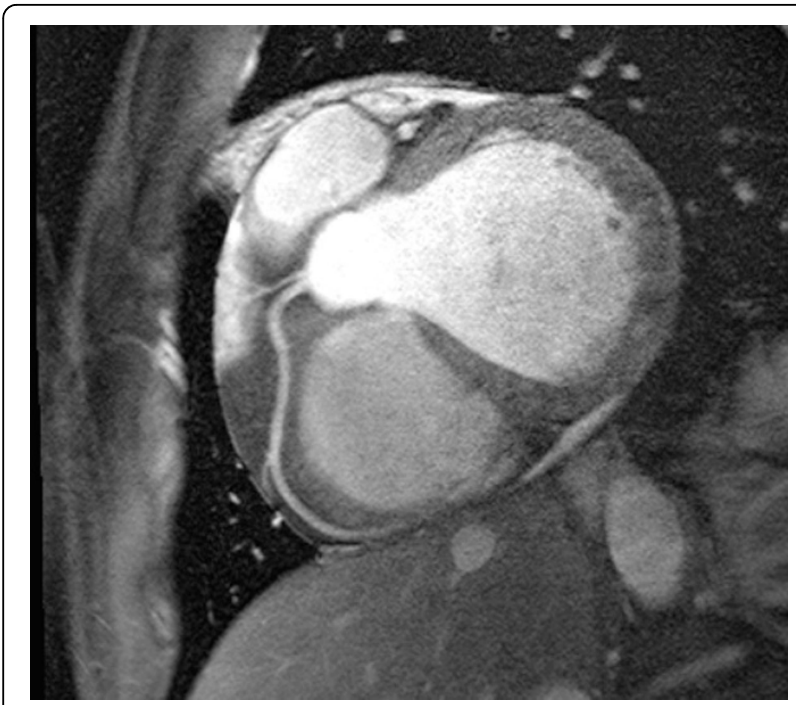

Figure 2

visualized segments was good, sub-optimal and non assessable in $88 \%, 2 \%$ and $10 \%$, respectively.

\section{Conclusions}

Hybrid PET/MRI does not compromise image quality and in addition provides clinically significant results for myocardial viability assessment.

\section{Funding}

Institutional Funding, Geneva University Hospitals.

\section{Author details}

${ }^{1}$ Geneva University Hospital, Geneva, Switzerland. '2Lausanne University Hospital, Lausanne, Switzerland.

Published: 1 February 2012 and take full advantage of:

- Convenient online submission

- Thorough peer review

- No space constraints or color figure charges

- Immediate publication on acceptance

- Inclusion in PubMed, CAS, Scopus and Google Scholar

- Research which is freely available for redistribution 